\title{
Editorial
}

\section{PHYSICIAN-SCIENTIST, ACADEMICIAN AND PUBLISHED RESEARCH AUTHOR}

Based largely on interest and preference, there are physician-scientists who are engaged in the dual work of being a clinician and researcher. Some of them have the added responsibility of also being academicians or members of medical faculties. The article, "Physician as Clinician, Researcher and Academician" in this JMUST issue demonstrates the importance of organizational support and collaboration for physicians. The doctor has multiple roles to navigate through three settings: clinics, research centers, and classrooms to fulfill the mission of better public health. Research and dissemination of findings through publication are almost sine qua non when the physician blends the roles of clinician, researcher, and academician. Within the purview of translational research, the clinician is informed and applies the knowledge base for better patient care.

We encourage all physicians to take on the additional role of researcher and contribute to the collaborative effort in investigating puzzling medical conditions of patients. Participation in research adds to not only evolving medical knowledge but also effective clinical practice and better patient outcomes.

After all, no matter how distinct the roles, they do share same values:

"Vision-clear sense of what one wants to accomplish in this world; Integrity-principles of life based on honesty and consistency; Dedication-hard work, persistence, and determination to move ahead despite setbacks; Curiosity-questions of why and how; and Confidence-a belief in yourself that allows one to challenge the dogma and take chances." [Schwartz DA. Editorial: Physician-Scientists, Am J Respir Crit Care Med 2012].

In this 2021 December issue, we have a total of 15 articles, constituting five clinical studies, two each for Public Health Action Research and Medical Education, and one each for Qualitative Research, Q Methodology Research, Meta-analysis, Case Report, Viewpoint, and Oration. Our cover page depicts the Philippine national hero, Jose P. Rizal, a physician educated at the University of Santo Tomas, a writer, and who on the fateful day of December 30th was executed because of activism. Fast forward, we consider him an inspiration, as we transcend our local boundaries as physician researchers to the global arena.

As we close the year 2021, we express our gratefulness to our advisory board, Philippine-based and international editorial board members who generously gave their time and expertise for JMUST to come up with two issues this year. We hope to publish three to four issues yearly in the coming years. We also thank our authors who shared their valuable research work for publication and our loyal readers. Soon, we will be on SCOPUS to cast a wider net in readership. 